\title{
O FIM DA LITERATURA: POSSIBILIDADES DE ENFRENTAMENTO
}

\section{THE END OF LITERATURE: POSSIBILITIES OF CONFRONTATION}

\author{
Diego Gomes do VALLE*
}

\begin{abstract}
Resumo:Há décadas, vaticina-se e aguarda-se o fim da literatura. Muitos críticos e teóricos da literatura lamentam e se ressentem por um futuro apocalíptico, que nunca chega. Este artigo parte dessa discussão e a aprofunda com vista a uma possível resolução nos campos da crítica e do ensino de literatura. Tratase, como desenvolvemos no artigo, de uma abordagem literária ao mesmo tempo especificizante e interdisciplinar, para assim o elemento humanizante surgir no mundo feito de papel. À guisa de exemplo, analisamos o poema "O monstrengo", que está no livro A balada do cárcere, de Bruno Tolentino. Desse modo, almejamos reunir, a um só tempo, diagnóstico, análise e, propositivamente, uma abordagem minimamente suficiente, diante desse estado de coisas.
\end{abstract}

Palavras-chave: Fim da literatura. A balada do cárcere. Humanização. Bruno Tolentino. Leitura.

\begin{abstract}
For decades, the end of literature has been predicted and awaited. Many critics and literature theorists lament and resent an apocalyptic future that never comes. This paperstarts from this discussion and deepens it with a view to a possible resolution in the fields of literature criticism and teaching. The text develops a specifying and interdisciplinary literary approach, so that the humanizing element appears in the world made of paper, as shown inthe analysis of the poem "O monstrengo", which is in the book A balada do cárcere, by Bruno Tolentino. Given this state of affairs, a proposal tobring diagnosis, analysis and a minimally sufficient approach is offered.
\end{abstract}

Keywords: End of literature. A balada do cárcere. Humanization. Bruno Tolentino. Reading.

\section{Entre pedras e páginas}

\author{
"Porque no princípio da literatura está o mito, e do mesmo \\ modo no fim". \\ Jorge Luis Borges, Parábola de Cervantes y de Quijote, \\ 1980 , p.336.
}

Jorge Luis Borges, no ensaio La muralla y los libros, discorre a respeito do imperador chinês que construiu a Muralha da China, apontando que, curiosamente, este mesmo sujeito operou uma grande queima de livros. Dirá o criador de El Aleph que não raro os governantes que se voltam para o pragmatismo de uma edificação concreta são os mesmos que buscam apagar o passado - "a rigorosa abolição da história" (BORGES, 1980, p.131, tradução nossa),e diminuir a capacidade crítica de seus cidadãos: "Por acaso o incêndio das bibliotecas e a

*Professor do Ensino Médio do Colégio Pontagrossense; Professor Colaborador da Universidade Estadual de Ponta Grossa (UEPG). Doutorado em Teoria e História Literária pela Universidade Estadual de Campinas (UNICAMP). Email: diegouab@gmail.com.

${ }^{1}$ No original: "Porque en el principio de la literatura está el mito, y asimismo en el fin".

${ }^{2}$ No original: "La rigurosa abolición de la historia". 
edificação da muralha são operações que de um modo secreto se anulam"3(BORGES, 1980, p.133, tradução nossa).

Utilizamos esta analogia como introdução porque entendemos que passamos por uma época semelhante, muito embora a megalomania do imperador seja substituída por outros fins pragmáticos atuais, sobre os quais trataremos à frente. Deste modo, pretendemos neste breve ensaio discorrer a respeito das possibilidades de enfrentamento do atual relativismo a respeito da legitimidade (ou não) da literatura e (por que não?) das Humanidades em geral, já que aquela é consequência desta. Para tal enfrentamento, propomos atitudes que partem do campo da crítica e do ensino da literatura, já que ambos são discursos mediadores entre as obras literárias e o público em geral.

A título de exemplo, analisaremos brevemente um poema de Bruno Tolentino, a partir do qual será possível, segundo nos parece, apresentar uma abordagem suficientemente satisfatória para atender ao que os mais conspícuos críticos e teóricos têm defendido nas últimas décadas a respeito do valor e respectivo trabalho com a literatura.

\section{O fim ou uma finalidade humanizante?}

\footnotetext{
"Hoje, se me pergunto por que amo a literatura, a resposta que vem espontaneamente à cabeça é: porque ela me ajuda a viver".

Tzvetan Todorov, A literatura em perigo, 2009, p.23.
}

Em livro recente, Mutações da literatura no século XXI (2016), Leyla Perrone-Moisés trata deste mesmo tema, no capítulo "O 'fim da literatura", fazendo um histórico dos "vários fins" que este nosso século acompanhou: fim das grandes narrativas, fim das utopias, fim do humanismo ${ }^{4}$, fim do romance, fim do sujeito logocêntrico etc. Contudo finaliza a ensaísta dizendo que "as notícias de minha morte foram muito exageradas" (PERRONE-MOISÉS, 2016, p.26), tomando de empréstimo a famosa frase de Mark Twain. Ou seja, para PerroneMoisés, há mais um sintoma apocalíptico, que reflete uma época de profundas mudanças, do que propriamente o fim: são "índices de mutações” (PERRONE-MOISÉS, 2016, p.17).

O fato é que em tempos de "turboconsumismo", conceito consagrado por Gilles Lipovetsky, a cultura do "mais rápido" e do "mais prático" encurrala a literatura, com sua

\footnotetext{
${ }^{3}$ No original: "Acaso el incendio de las bibliotecas y la edificación de la muralla son operaciones que de un modo secreto se anulan".

${ }^{4} \mathrm{Na}$ peça $O$ rinoceronte, de 1959, Eugène Ionesco coloca na boca de Jean (prestes a se transformar em rinoceronte) as seguintes palavras: "Bérenger: Eu me referia ao ser humano, à humanidade... Jean: O humanismo caducou! Você é um sentimentalão ridículo" (IONESCO, 2015, p.83).
} 
lentidão e isolamento, ao domínio quase que marginal de uma casta excêntrica, na qual a crise das humanidades encontra seu paroxismo. Neste império do tecnicismo, a simultaneidade e a velocidade são valores supremos, diante dos quais a literatura é retrógrada ou, como diz Maurice Blanchot, é "auxiliar da cultura"5; é mero "inutensílio", como disse Leminski 6 , embora com uma conotação revolucionária, que é própria ao discurso literário.

Em um dos mais célebres e tocantes manifestos deste fim que ora discorremos, $A$ literatura em perigo, Todorov, fazendo mea culpa, chama a atenção para o papel da crítica literária, sustentando que o viés estruturalista (do qual ele foi um dos maiores expoentes) contribuiu fortemente neste processo de desvalorização da obra literária enquanto produto cultural para o público não especializado: "Não apenas estudamos mal o sentido de um texto se nos atemos a uma abordagem interna estrita, enquanto as obras existem sempre dentro e em diálogo com um contexto" (TODOROV, 2009, p.32). Enquanto objeto de culto formal, a literatura se afasta do sujeito comum e passa a ser domínio de uma elite encastelada em seus hermetismos conceituais. Como se nota, estávamos a léguas do conceito de humanização via literatura, de Antonio Candido.

É neste sentido que a crítica literária exerce poder de destruição ou restauração das potencialidades do discurso literário. Como grande contribuição nacional, o ensaio $O$ direito à literatura, de Antonio Candido, ataca frontalmente este problema. Fruto de uma palestra feita no período de redemocratização (1988), o professor e crítico percebe que, em época de "indústria cultural" (Adorno e Horkheimer), o que falta é humanidade ao ser humano reificado pela dinâmica do capital. Neste contexto, Candido apresenta a famosa distinção ${ }^{7}$ entre "bens compressíveis" e "bens incompressíveis", designando que os primeiros podem ser vedados a certos grupos, pois são dispensáveis num nível básico de existência; já os segundos são absolutamente indispensáveis para a manutenção de certo aspecto humano. É precisamente entre os "incompressíveis" que se localiza a literatura.

Dirá o crítico que a literatura "não corrompe, nem edifica, mas, trazendo livremente em si o que chamamos o bem e o que chamamos o mal, humaniza em sentido profundo, porque faz viver" (CANDIDO, 2004, p.176). Deste modo, se a crítica pode enfrentar este "fim da

\footnotetext{
5 “A arte não é mais capaz de portar a necessidade de absoluto [...] A arte só está próxima do absoluto no passado, e é apenas no museu que ela ainda tem valor e poder. Ou então, desgraça mais grave, ela decai em nós até tornarse simples prazer estético, ou auxiliar da cultura" (BLANCHOT apud PERRONE-MOISÉS, 2016, p.21).

6 "O lucro da poesia, quando verdadeira, é o surgimento de novos objetos no mundo. Objetos que signifiquem a capacidade da gente de produzir mundos novos. Uma capacidade in-útil. Além da utilidade" (LEMINSKI, 2014, p.48).

${ }^{7}$ A distinção, cabe lembrar, não é dele, mas do Padre Louis-Joseph Lebret.
} 
literatura", é por meio de uma atitude que, embora de modo sutil e que necessita de uma contrapartida do ensino, evidencie tal processo de humanização. Aliás, Todorov se assemelha muito a Candido neste ponto: "Longe de ser um simples entretenimento, uma distração reservada às pessoas educadas, ela permite que cada um responda melhor à sua vocação de ser humano" (TODOROV, 2009, p.24). É neste sentido que a literatura só pode ser “incompressível”, um direito inalienável.

Desse modo, assim como os críticos evocados, compreendemos que a finalidade da literatura reside em sua profunda, delicada e pouco pragmática função humanizadora. Contudo, onde reside tal função?

\title{
2. Onde está o humano no papel?
}

\author{
"O mundo, segundo Mallarmé, existe para um livro; \\ segundo Bloy, somos versículos ou palavras ou letras de um \\ livro mágico, e esse livro incessante é a única coisa que há \\ no mundo: é, melhor dizendo, o mundo"8. \\ Jorge Luis Borges, "Del culto de los libros", 1980, p.233, \\ tradução nossa.
}

Vincent Jouve, em Por que estudar literatura? (2012), de modo abrupto, mas propositivo, diz:

\begin{abstract}
Digamos sem rodeios: os estudos literários só podem ter legitimidade se resultarem em algo útil para a sociedade. Portanto, não basta 'provar' (supondo-se que seja possível) que esse poema é belo: é preciso mostrar que ele enriquece nossa compreensão do mundo, esclarecendo-nos sobre o que somos e sobre a realidade em que vivemos (JOUVE, 2012, p.139).
\end{abstract}

Ou seja, há de se tratar a literatura, antes de qualquer coisa, como fonte de conhecimento, tão legítima quanto as demais. A beleza de um verso - que não precisa e não se presta a ter utilidade prática - evidentemente melhora e amplia o status humano. Contudo, segundo a perspectiva escolhida por nós, a literatura pode mais, de um modo que só ela pode, mas que necessita de uma abordagem intertextual, interdisciplinar, intersemiótica, resiliente e, mais do que isso, consiliente ${ }^{9}$.

\footnotetext{
${ }^{8}$ No original: "El mundo, según Mallarmé, existe para un libro; según Bloy, somos versículos o palabras o letras de un libro mágico, y ese libro incesante es la única cosa que hay en el mundo: es, mejor dicho, el mundo".

${ }^{9}$ Criado pelo cientista Edward Wilson, o termo, no sentido estrito, é um "salto conjunto do conhecimento pela ligação de fatos em todas as disciplinas para criar uma base comum de explicação" (WILSON, 1999, p.7). Utilizamos o termo no sentido lato, enquanto esforço conjunto e aprofundado, pois, no sentido estrito, Wilson busca desmi(s)tificar as ciências humanas, "folclóricas" para o autor.
} 
Assim, à guisa de exemplo, traremos um soneto de autoria de Bruno Tolentino, $O$ monstrengo, pois nos possibilitará explorar precisamente uma forma de enfrentamento. $\mathrm{O}$ poema pertence ao livro A balada do cárcere:

\author{
O monstrengo \\ "Tive tudo o que quis, e o que não quis \\ também, é claro; mas ressalvo a audácia \\ com que arranquei à pedra da desgraça \\ uma felicidade de infeliz; \\ Martelei pedra viva e dei-lhe a face \\ que esculpi: tive assim, não o que quis, \\ mas o rosto que tenho, traço a traço, \\ fui eu que o inventei, fui eu que o fiz! \\ A Medusa morreu: matei-a eu \\ e a espécie de Perseu que fiquei sendo \\ não foi a ilustre morta que me deu. \\ Fui eu mesmo que fiz este monstrengo, \\ o inútil monumento é todo meu. \\ Eu, modelo, martelo e monumento!" (TOLENTINO, 1996, p.58).
}

Faz-se necessário esclarecer que este soneto compõe uma série dentro do livro supracitado de Tolentino, o qual escreveu tal obra em circunstâncias muito peculiares. Tolentino passou alguns anos em uma prisão do Reino Unido e lá desempenhou um trabalho louvável com os demais presidiários: apresentar a literatura aos detentos como forma de apreensão da realidade e de si mesmo. Trata-se daquilo que Michèle Petit chama de "biblioterapia" em seu livro A arte de ler ou como resistir à diversidade, em que a antropóloga leva a literatura a "espaços de crise" espalhados pelo mundo afora:

Não importa o meio onde vivemos e a cultura que nos viu nascer, precisamos de mediações, de representações, de figurações simbólicas para sair do caos, seja ele exterior ou interior. $\mathrm{O}$ que está em nós precisa primeiro procurar uma expressão exterior, e por vias indiretas, para que possamos nos instalar em nós mesmos (PETIT, 2009, p. 115).

Deste modo, Tolentino conheceu Nick, figura principal da obra, o qual havia matado sua esposa e que vai encenar o "drama da inarticulação" desenvolvido em A balada do cárcere:

Condenado à prisão perpétua pelo assassinato da esposa em 1980, levou a cabo em cerca de dois anos uma completa revolução em seu modo de ver, e de ver-se. Sob minha supervisão pessoal, passou de analfabeto belicoso a aluno dedicado, leitor assíduo de matérias cada vez mais complexas (TOLENTINO, 1996, p.13). 
Desse modo, o livro de poemas A balada do cárcere é uma sequência na qual (e por meio da qual) Nick consegue linguagem ${ }^{10}$, via literatura, para sair de seu labirinto pessoal em que o fio de Ariadne (a forma construída em que suas emoções encontram guarida) acaba sendo o próprio discurso literário, já que "a vantagem é que a informação transmitida pela literatura tem uma força de impacto que o discurso racional não pode ter: ela é 'sentida' antes de ser entendida, portanto, sem ser compreendida" (JOUVE, 2012, p.136).

Tratava-se, logo, de descobrir as razões, dinamizar a culpa por ter dado fim à vida de quem (contraditoriamente) mais amava, como comenta o autor na introdução do livro:

nada menos que a linguagem da poesia poderia dar conta da formidável riqueza de símbolos e metáforas vivas através das quais aquele espírito conturbado buscava desesperadamente dar forma verbal inteligível ao universo fantasmagórico que habitava (TOLENTINO, 1996, p.14).

Neste soneto, Nick relata - por meio do fingimento poético do eu-lírico - justamente como ele concebe o crime cometido, analogando à arte da escultura em pedra o ato vil cometido. Aliás, o campo semântico rochoso é evocado já no título, em que $O$ monstrengo, de Fernando Pessoa, poema que compõe seu Mensagem, alude ao episódio do Gigante Adamastor, de $O s$ lusíadas, de Camões.Sabe-se que Bartolomeu Dias, o "Capitão do Fim”, havia dobrado o continente africano em 1488, mas que somente Vasco da Gama completaria a viagem até as Índias em 1497-1499. Ao lado do Cabo do Bojador, o Cabo Tormentório (ou das Tormentas) guardava em si o assombro mortal aos que ousadamente anelavam fazer a dobradura no continente. Vencer o assombro significava, então, superar o desconhecido: ao mesmo tempo em que se vencia a morte, descobria-se nova vida, ampliava-se o domínio. Precisamente como ocorre quanto aos meandros sutis e problemáticos de nosso caos emocional. E aí o drama da inarticulação de Nick passa a ser plenamente universal, a partir de um jogo de espelhos pedregoso.

Desse modo, em uma dinâmica ambivalente de intertextualidade, o drama do feminicida encontra imagens consagradas em dois dos maiores escritores de nossa língua. Ou seja, a dureza de sentimentos, o campo semântico rochoso, o medo do desconhecido (ele mesmo e a travessia do Cabo Tormentório) e a dor vão dialogando intertextualmente na voz do homicida (não nos

\footnotetext{
10 ““Nick’ não era, a rigor, apenas mais um entre os detentos. Grave, inabordável, intimidante mesmo, não era um criminoso contumaz, nem um maníaco sexual, nem um violento compulsivo. Seu drama tinha menos de patológico que de exemplar: com efeito, eu jamais havia encontrado alguém tão inarticulado, tão selvagem ante os impassíveis portais da linguagem simbólica, nem mais indiferente à via larga da conversação trivial, da interação a nível corrente" (TOLENTINO, 1996, p.13).
} 
esqueçamos que todo o soneto é emoldurado por aspas, que conservam o valor de relato, de confissão moral e amorosa).

Para alimentar tal périplo intertextual, cabe recordar que o Gigante Adamastor, titã mitológico filho de Gaia, primeiramente se apresenta de modo amedrontador aos portugueses, ameaçando e profetizando desastres ao ínclito povo português. Contudo, na sequência, o Gigante mostra sua faceta amorosa, como que confidenciando sua mal fadada experiência com Thétis. Enquanto força telúrica, associado às forças naturais (Gaia), Adamastor representa, no aspecto que nos interessa, a desproporcionalidade, o monstruoso, o "inútil monumento" 11 . Desse modo, o amor de ninfa nunca seria o bastante, fato que o autoriza a usar sua descomunal força: “Como fosse impossíbil alcançá-la,/ Pela grandeza feia de meu gesto,/ Determinei por armas de tomá-la" (CAMÕES, 2008, p.126).Esta é a principal nota que associamos entre os dois monstrengos: a força violenta a serviço do amor desordenado.

Desde os gregos, toda desmedida (hÿbris) é severamente penalizada. No caso de Adamastor, o gigante foi condenado a rebaixar-se ontologicamente ao nível mineral, porém, ainda consciente de seu opróbrio. Ou seja, inerte, inapto, mas não inconsciente, Adamastor constantemente revive seu fado, sua dor moral, a impossibilidade de realização amorosa, bem como o inescapável enfrentamento de sua condição. Um enredo perfeito para se ilustrar conforme Denis de Rougemont, em seu $\mathrm{O}$ amor e o Ocidente - a concepção trágica e tradicional de amor:

\begin{abstract}
O amor feliz não tem história. Só existem romances do amor mortal, ou seja, do amor ameaçado e condenado pela própria vida. O que o lirismo ocidental exalta não é o prazer dos sentidos nem a paz fecunda do par amoroso. É menos o amor realizado que a paixão do amor. E paixão significa sofrimento. Eis o fato fundamental (ROUGEMONT, 1988, p.17).
\end{abstract}

Desse modo, precisamente como o monstrengo de Tolentino, Adamastor ilustra a noção de amor mortal, de que trata Rougemont em sua clássica obra e que está incrustada nos mitos e na literatura ${ }^{12}$.

\footnotetext{
${ }^{11}$ Vemos no Dicionário de símbolos que: "Os gigantes foram postos no mundo pela Terra (Gaia) para vingar os Titãs que Zeus encerrara no Tártaro. São seres ctonianos que simbolizam a predominância das forças saídas da terra por seu gigantismo material e indigência espiritual. Imagem do desmesurado, em benefício dos instintos corpóreos e brutais [...] O gigante representa tudo aquilo que o homem tem de vencer para libertar e expandir sua personalidade" (CHEVALIER; GHEERBRANT, 2009, p.470).

12 "A obscuridade do mito nos permite, portanto, aceitar seu conteúdo disfarçado e desfrutá-lo na imaginação, mas sem tomarmos uma consciência bastante clara para que a contradição se manifeste. Deste modo, determinadas realidades humanas que sentimos ou pressentimos como fundamentais estão fora do alcance da crítica. $\mathrm{O}$ mito exprime essas realidades, na medida em que nosso instinto o exige, mas também as disfarça, na medida em que seriam ameaçadas pelo grande despertar da razão" (ROUGEMONT, 1988, p.21).
} 
Por meio de decassílabos heroicos martelo (tônicas nas $3^{\mathrm{a}}, 6^{\mathrm{a}}$ e $10^{\mathrm{a}}$ sílabas poéticas), o eulírico mostra como só é possível talhar a própria face de modo negativo, ou seja, retirando talhos de si mesmo. $\mathrm{O}$ verso $6^{\circ}$ possui harmonia imitativa perfeita nesse sentido, pois a pedra bruta sendo burilada necessariamente fornecerá sons agudos, os quais necessitam da mais aguda das vogais: "que esculpi", "tive assim, não o que quis". Eis a explicação do oximoro "felicidade de infeliz": lograr êxito em algo terrível e que é a sua própria destruição.

Fica evidente que se trata de, no poema, o eu-lírico como que purgar sua culpa, há tempos sendo martelada dentro de si. É sintomático que o pronome pessoal "eu” apareça cinco vezes, além dos possessivos e da forma pleonástica no $9^{\circ}$ verso: "matei-a eu", que reforçam o drama de consciência em jogo.

A menção mitológica, na terceira estrofe, intensifica o campo semântico da pedra, mas se contrapõe à nobreza do herói mítico que deu cabo à górgona famosa: não há nada de positivo aqui, só a culpa dilacerante, como o cinzel que rompe a face do eu-lírico. Do mesmo modo, a figura de um ser feminino que petrifica o outro ao mesmo tempo em que recebe morte violenta pode ser analogada à versão do feminicida Nick. Sintomaticamente, o Dicionário de símbolos registra no verbete "Górgonas" a noção de culpa relacionada à Medusa:

\footnotetext{
Quem via a cabeça da Medusa ficava petrificado. Não seria por refletir a Górgona a imagem de uma culpa pessoal? [...] A Medusa simboliza a imagem deformada do eu... que petrifica ao invés de esclarecer na medida justa" (CHEVALIER; GHEERBRANT, 2009, p.476).
}

Nesta breve análise, buscamos exemplificar aquilo que alertou Jouve como necessário aos estudos literários, a saber: por meio de uma obra literária, aumentarmos nossa compreensão do mundo e do eu. O drama de Nick torna-se universal na medida em que a forma literária enquadra conteúdos humanos permanentes:

\footnotetext{
Quer percebamos claramente ou não, o caráter de coisa organizada da obra literária torna-se um fator que nos deixa mais capazes de ordenar a nossa própria mente $\mathrm{e}$ sentimentos; e, em consequência, mais capazes de organizar a visão que temos do mundo (CANDIDO, 2004, p.176).
}

Deste modo, a prisão de Nick é redimensionada conforme as restrições dos leitores e percebemos que todos estamos aprisionados de certa forma.Mia Couto, em Versos do prisioneiro, encerra o poema dizendo: "Quando abrirem as portas/ Eu serei, enfim/ meu único carcereiro" (COUTO, 2016, p.52). Sendo assim, a literatura, como modo de enfrentar sua crescente deslegitimação, precisa ser concebida como forma de linguagem que nos humaniza, 
na medida em que, como disse Ludwig Wittgenstein, no aforismo 5.6 de seu Tractatus: "os limites do meu ser são os limites da minha linguagem” (WITTGENSTEIN, 1968).

\title{
3. Leitura literária e ontologia
}

\author{
"A literatura não é esgotável, pela suficiente e simples razão \\ de que um só livro não o é. O livro não é um ente \\ incomunicado: é uma relação, é um elo de inumeráveis \\ relações"13. \\ Jorge Luis Borges, "Nota sobre (hacia) Bernard Shaw", \\ 1980, p.272, tradução nossa.
}

Outra linha de enfrentamento seria o ensino de literatura, já que, na esfera do Estado, a grande questão é a de se são legítimas as políticas de fomento nesta área especificamente, em tempos de contingenciamentos de verbas públicas.

Como proposição razoavelmente recente, temos o conceito de letramento literário, que tem como seu principal expoente, aqui no Brasil, o professor Rildo Cosson. Em sua obra mais famosa, Letramento literário: teoria e prática, Cosson admite, com Magda Soares, que a literatura, quando entra na escola, escolariza-se, entra na dinâmica curricular e, enquanto saber escolarizado, adequa-se à finalidade do ensino ${ }^{14}$.

Trata-se, segundo o professor, de "apropriar-se"15 da literatura de modo que esta arte amplie o campo de possibilidades que cercam o ser humano: "a função essencial de construir e reconstruir a palavra que nos humaniza" (COSSON, 2014, p.23).James Wood, em Como funciona a ficção, ilustra esta ideia dizendo que "a literatura nos ensina a notar melhor a vida; praticamos isso na vida, o que nos faz, por sua vez, ler melhor o detalhe na literatura, o que, por sua vez, no faz ler melhor a vida" (WOOD, 2012, p.63). Ou seja, indefinidamente seguiremos

\footnotetext{
${ }^{13}$ No original: "La literatura no es agotable, por la suficiente y simple razón de que un solo libro no lo es. El libro no es un ente incomunicado: es una relación, es un eje de innumerables relaciones".

${ }^{14}$ Não entraremos na espinhosa questão da literatura ensinada com vistas aos processos de seleção para o ingresso no Ensino Superior. Contudo, registramos nossa compreensão de que o leitor literário, de que tratamos nesta seção, não é o mesmo leitor-de-vestibular, uma vez que, nesta circunstância, lê-se de modo técnico, selecionando de modo mais ou menos objetivo (e daí a grande diferença com relação ao que a leitura literária realmente é) elementos do texto literário com vistas ao certo ou ao errado, conforme certo perfil de prova.

15“Ao ler, estou abrindo uma porta entre o meu mundo e o mundo do outro. O sentido do texto só se completa quando esse trânsito se efetiva, quando se faz a passagem de sentidos entre um e outro. Se acredito que o mundo está absolutamente completo e nada mais pode ser dito, a leitura não faz sentido para mim" (COSSON, 2014, p.27).
} 
tornando mais sutil a nossa percepção dos fenômenos humanos, desde que mediada pelo alumbramento literário ${ }^{16}$. Jorge Luis Borges, em "Nota sobre (hacia) Bernard Shaw", diz que:

Um livro é mais que uma estrutura verbal, ou que uma série de estruturas verbais: é um diálogo que estabelece com seu leitor e a entonação que impõe a sua voz e as cambiantes e duráveis imagens que deixa em sua memória. Esse diálogo é infinito(BORGES, 1980, p.271) ${ }^{17}$.

Nesse infinito diálogo, o processo de humanização pode ser analisado a partir de uma perspectiva fenomenológica, já que se trata sempre de uma consciência - que é sempre consciência de alguma coisa, conforme Husserl -diante de um texto. Vincent Jouve, apoiado em teóricos da recepção e em filósofos alinhados ao viés da fenomenologia, explora o assunto em A leitura. Para Jouve, glosando Jauss, na leitura literária ocorrem dois tipos de liberdade: liberdade de alguma coisa e liberdade para alguma coisa. Ou seja, o leitor se livra de algo de sua vida empírica e, ipso facto, é livre para algo ou para ser alguém que não o é no real-real. Desse modo, chega-se a "uma das experiências mais emocionantes da leitura [que] consiste em proferir mentalmente ideias que não são as nossas" (JOUVE, 2002, p.109).

Esse efeito de vertigem, é necessário admitir, não é estritamente bom, no sentido de agradável, prazeroso, mas necessariamente amplia o campo de experiências humanas do sujeito: "Essa interiorização do outro - é fácil admiti-lo - perturba quanto fascina. Ser quem não somos (mesmo para um tempo relativamente circunscrito) tem algo de desestabilizante" (JOUVE, 2002, p.109). Com efeito, essa voluntária entrega de um território de consciência a um outro ser (que não sou eu e ao mesmo tempo não é outro) como que enforma, ou seja, dá forma às nossas próprias experiências. Daí o efeito de identificação entre leitor-texto ou leitorexperiência representada na obra, que pode ser maior ou menor, mas que nunca é neutra ${ }^{18}$.

Tal efeito ontológico só pode ser levado a cabo, na dimensão do cidadão comum, na esfera do ensino. Ou seja, como queria Candido, deve ser um “direito inalienável”, já que sua ausência

\footnotetext{
${ }^{16}$ Vincent Jouve, em Por que estudar literatura?, diz: "um romance nos ensina muito pouco sobre o amor ou sobre a morte, mas infinitamente mais sobre a relação com o amor ou com a morte" (JOUVE, 2012, p.101).

${ }^{17}$ No original: "un libro es más que una estructura verbal, o que una serie de estructuras verbales; es un diálogo que entabla con su lector y la entonación que impone a su voz y las cambiantes y durables imágenes que deja en su memoria. Ese diálogo es infinito".

18 À guisa de exemplo desta identificação, é arquiconhecido o fato de os leitores de Os sofrimentos do Jovem Werther, de Goethe, terem tirado suas próprias vidas, acompanhando o melancólico protagonista do romance. Sabe-se também que um jovem russo, perturbadoramente empolgado com a tese de Raskólnikov, de Crime $e$ castigo, justificou um homicídio (com o requinte das mesmas machadadas do herói de Dostoiévski) após ter se embebido da ambiência do estudante russo. Por outro lado, o clássico O Festim diabólico (1948), de Alfred Hitchcock, encena o modo como certas noções filosóficas alienaram dois estudantes, de modo bem raskolnikoviano, a ponto de sacrificarem um colega para imprimirem sua tese.
} 
pode mutilar a personalidade do sujeito ${ }^{19}$. Doravante, neste ponto, crítica, teoria e ensino se entrelaçam, pois não é provável que um docente consiga chegar a este nível de aproveitamento da obra literária somente como entusiasta ou enfatizando estritamente o aspecto lúdico do texto (quando há) ou a fruição prazerosa de certa obra (novamente, quando há):

Na escola, a leitura literária tem a função de nos ajudar a ler melhor, não apenas porque possibilita a criação do hábito de leitura ou porque seja prazerosa, mas sim, e sobretudo, porque nos fornece, como nenhum outro tipo de leitura faz, os instrumentos necessários para conhecer e articular com proficiência o mundo feito linguagem (COSSON, 2014, p.30).

Mario Vargas Llosa, no famoso ensaio Em defesa do romance, menciona que Bill Gates previra o fim do livro para breve e que não haveria mais espaço para uma relação como esta de que estamos tratando. Embora, de uma perspectiva humanista e liberal, chegue a conclusões semelhantes às do socialista Antonio Candido, dizendo que o fim do romance/literatura implicaria necessariamente na perda de certa linguagem a respeito de questões humanas fundamentais:

Incivilizado, bárbaro, órfão de sensibilidade e pobre de palavra, ignorante e grave, alheio à paixão e ao erotismo, o mundo sem romances, esse pesadelo que procuro delinear, teria como traço principal o conformismo, a submissão dos seres humanos ao estabelecido. Seria um mundo animal (LLOSA, 2009, s/p).

Já Milan Kundera, em $A$ arte do romance, diz que a literatura explora a existência humana, traça um "mapa existencial" no qual nos reconhecemos e a partir do qual saltamos de nós mesmos em direção ao outro. Embora Daniel Pennac diga em seu Como um romance que o primeiro direito do leitor deve ser o de "não ler", caso ele o faça, deve subjazer um conceito de literatura minimante semelhante a este indicado pelos críticos evocados. Ademais, a observação final do pensador francês é muito percuciente:

A ideia de que a leitura "humaniza o homem" é justa no todo, mesmo se ela padece de algumas deprimentes exceções [...] Mas evitemos vincular a esse teorema o corolário segundo o qual todo indivíduo que não lê poderia ser considerado, em princípio, como um bruto potencial ou um absoluto cretino. Nesse caso, faremos a leitura passar por obrigação moral (PENNAC, 1993, p.144).

Desse modo, concordando com a observação de Pennac, não se trata de fazer uma apologia elitista e, no nosso caso, autoglorificante, mas de, em termos objetivos, indicar aquilo

\footnotetext{
${ }^{19}$ Novamente, Vincent Jouve diz: “Ao nos envolver em um mundo que não é a realidade, mas que se assemelha a ela, as ficções nos levam, portanto, a reavaliar o mundo onde vivemos” (JOUVE, 2012, p.121).
} 
que somente a literatura pode oferecer com tal intensidade, o seu traço distintivo, que é o de ampliar a nossa existência de modo sutil e insuspeito. Por outro lado, se há uma possibilidade de se assegurar a manutenção da literatura ao cidadão comum, é mister que ela seja tratada como tal na dimensão do ensino básico, e não somente nos cursos de Letras, por exemplo. Registramos com veemência este ponto, pois, como sabemos, a crítica literária não desempenha, como em outros tempos, papel de instrução e mediação massiva junto ao público leitor médio e não especializado.

\section{Considerações finais}

Sabe-se que no século XIX perguntava-se, a sério, o que seria mais útil: Skakespeare ou um par de botas? A pergunta - capciosa, diga-se - evidencia o olhar utilitarista, pragmático e que era nascente naqueles idos, muito corrente nos dias atuais. Conforme vimos, se há alguma utilidade para a literatura, ela não é pragmática, mas mais sutil e, por isso mesmo, fundamental.

Entre muralhas erguidas e livros ardendo, o que possibilitará a restituição das cinzas, a percepção da prisão existencial em que todos estamos, é a ação humana mediadora entre livros e sujeitos, ou seja, a crítica literária e o ensino.

Buscamos, nesse breve artigo, trazer um conceito de literatura que vem sendo defendido pelos diversos críticos e teóricos da literatura há pelo menos meio século e otimizá-lo na análise do poema de Bruno Tolentino, que, por sua vez, encena o próprio poder da literatura defendido pelos pensadores evocados. Desse modo, cremos ter exemplificado - não de modo normativo, esperamos ter ficado evidente - como valorizar aquilo que é próprio da literatura, mas em diálogo com outros discursos que nos rodeiam. Pois, como diz Barthes: "Se, por não sei que excesso de socialismo ou de barbárie, todas as nossas disciplinas devessem ser expulsas do ensino, exceto numa, é a disciplina literária que devia ser salva, pois todas as ciências estão presentes no monumento literário" (BARTHES, s/a, p.16).

Jorge Luis Borges, sempre ele, diz em Sobre los clásicos que "A glória de um poeta depende, em suma, da excitação ou da apatia das gerações de homens anônimos que a põem à prova, na solidão de suas bibliotecas”(BORGES, 1980, p.303, tradução nossa) ${ }^{20}$. Críticos e docentes precisam evidenciar que pares de botas envelhecem e têm prazos de validade, ao passo que o criador de Hamlet tem mantido sua contemporaneidade.

\footnotetext{
${ }^{20}$ No original: "La gloria de un poeta depende, en suma, de la excitación o de la apatia de las generaciones de hombres anónimos que la ponen a prueba, en la soledad de sus bibliotecas".
}

Revista Graphos, vol. 22, n 2, 2020 | UFPB/PPGL | ISSN 1516-1536 


\section{Referências}

BARTHES, Roland. Aula. Trad. Leyla Perrone-Moisés. São Paulo: Cultrix, s/a. Disponível em: $<$ https://edisciplinas.usp.br/pluginfile.php/160637/mod_resource/content/1/BARTHES_R oland___Aula.pdf $>$.Acesso em: 31 jan. 2020.

BORGES, Jorge Luis. La muralla y los libros. In: .Prosa Completa. v.2. Barcelona: Bruguera, 1980.

CAMÕES, Luís de. Obra completa. Org. Prof. Antônio Salgado Júnior. Rio de Janeiro: Editora Nova Aguilar, 2008.

CANDIDO, Antonio. O direito à literatura. In: .Vários escritos. São Paulo/Rio de Janeiro: Duas Cidades, 2004.

CHEVALIER, J.; GHEERBRANT, A. Dicionário de símbolos. Trad. Vera da Costa e Silva. Rio de Janeiro: José Olympio, 2009.

COSSON, Rildo. Letramento literário: teoria e prática. 2. ed. São Paulo: Contexto, 2014.

COUTO, Mia. Poemas escolhidos. Apresentação de José Castello. São Paulo: Companhia das Letras, 2016.

IONESCO, Eugène. O rinoceronte. Trad. Luis de Lima. Rio de Janeiro: Nova Fronteira, 2015.

JOUVE, Vincent. Por que estudar literatura? Trad. Marcos Bagno e Marcos Marcionilo. São Paulo: Parábola, 2012.

JOUVE, Vincent. A leitura. Trad. Brigitte Hervot. São Paulo: Editora Unesp, 2002.

LEMINSKI, Paulo. Ensaios e anseios crípticos. Curitiba: Editora Inventa, 2014.

LLOSA, Mario Vargas. Em defesa do romance. Revista Piauí. Edição 37, Outubro, 2009. Disponível em: <https://piaui.folha.uol.com.br/materia/em-defesa-do-romance/>. Acesso em: 30 jan. 2020.

PENNAC, Daniel. Como um romance. Trad. Leny Werneck. Rio de Janeiro: Rocco, 1993.

PERRONE-MOISÉS, Leyla. Mutações da literatura no século XXI. São Paulo: Companhia das Letras, 2016.

PETIT, Michèle. A arte de ler ou como resistir à adversidade. São Paulo: Editora 34, 2009.

ROUGEMONT, Denis de. O amor e o Ocidente. Trad. Paulo Brandi e Ethel Brandi Cachapuz. Rio de Janeiro: Editora Guanabara, 1988. 
TODOROV, Tzvetan. A literatura em perigo. Trad. Caio Meira. Rio de Janeiro: Difel, 2009. TOLENTINO, Bruno. A balada do cárcere. Rio de Janeiro: Topbooks, 1996.

WILSON, Edward. Consiliência: a unidade do conhecimento. Rio deJaneiro: Campus, 1999. WITTGENSTEIN, Ludwig. Tractatus Logico-Philosophicus. Trad. José Arthur Giannotti. São Paulo: Companhia Editor Nacional/ Editora da Universidade de São Paulo, 1968.

WOOD, James. Como funciona a ficção. Trad. Denise Bottmann. São Paulo: Cosac Naify, 2012.

Recebido em: 09/04/2020

Aceito para publicação em: 18/08/2020 